\title{
Electrochemical Behaviour of Dopamine at Covalent Modified Glassy Carbon Electrode with L-Cysteine: Preliminary Results
}

\author{
Carlos Alberto Martínez-Huitle ${ }^{\mathrm{a}, \mathrm{c}}$, Monica Cerro-Lopez ${ }^{\mathrm{b}}$, Marco Antonio Quiroz $^{\mathrm{b}}$ \\ a'Laboratory of Electrochemistry, Department of Analytical Chemistry, \\ University of Milan, \\ via Celoria 2, 20133 - Milan, Italy \\ ${ }^{\mathrm{b}}$ Departamento de Química y Biología, Universidad de las Américas - Puebla \\ 72820 - Puebla, Mexico \\ ${ }^{c}$ Departamento de Química, Centro de Ciências Exatas e da Terra, \\ Universidade Federal do Rio Grande do Norte, \\ Lagoa Nova CEP 59078-970 - Natal, RN, Brazil
}

Received: October 10, 2008; Revised: November 13, 2009

\begin{abstract}
The surface of glassy carbon (GC) electrode has been modified by oxidation of L-cysteine. The covalent modified GC electrode with L-Cysteine has been studied, according the supporting electrolyte used. Favourable interactions between the L-cysteine film and DA enhance the current response compared to that at the Nafion GC and bare GC electrodes, achieving better performances than those other electrodes. This behaviour was as result of the adsorption of the cysteine layer film, compact and uniform formation; depending on L-cysteine solution (phosphate buffer or chloridric acid supporting electrolyte) used for modifying GC surface. In cyclic voltammetric measurements, modified electrodes can successfully separate the oxidation/reduction DA peaks in different buffer solutions, but an evident dependence in the response was obtained as function of $\mathrm{pH}$ and modified electrode. The modified electrode prepared with L-cysteine/ $\mathrm{HCl}$ solution was used to obtain the calibration curve and it exhibited a stable and sensitive response to DA. The results are described and discussed in the light of the existing literature.
\end{abstract}

Keywords: dopamine, glassy carbon electrode, cyclic voltammetry, modified electrode, L-Cysteine

\section{Introduction}

Dopamine (DA) is a most common excitatory chemical neurotransmitter, plays an important role in the function of the central nervous system, renal, hormonal and cardio vascular systems ${ }^{1-3}$. For example, the deficiency of DA can result in some grave diseases such as schizophrenia and Parkinson's disease ${ }^{2-3}$. In neurotransmission process, a selective binding of neurotransmitter with the specific receptor is very important. In in vivo binding strategy, hydrophobic aromatic interaction is an important factor that is responsible for selective binding in comparison with other factors, such as ionic interaction and hydrogen bonding ${ }^{4-6}$. In neuropharmacology and neurophysiology the detection of DA is a challenging task.

The development of micro/biosensors or modified electrodes is attractive avenue for in vivo measurements of metabolites such as glucose, hormones, and neurotransmitters ${ }^{7,8}$. Since metabolites can vary substantially over a period of a few minutes, such microbiosensors that can function in the tissues or bloodstream may become a powerful tool for clinical and neurochemical monitoring. In addition, they should provide the means to characterize the neurochemical microenvironment during nerve cell stimulation and pharmacological manipulations ${ }^{8}$.

Methods for the detection of DA include fluorimetry, chemiluminescence, ultraviolet-visible spectrometry and capillary electrophoresis (CE-luminescence) $)^{9-12}$. However; the electroactivity of DA allows its determination by electrochemical methods. Electrochemical techniques have attracted great interest in many cases, and these techniques can be fast in detection, low in cost, and with the merits of low detection limit and high accuracy. The cyclic voltammetric response for DA has been studied at a variety of modified electrode surfaces ${ }^{13-23}$. In recent years, carbon nanotubes have been widely used as electrochemical sensors and biosensors ${ }^{24}$. Therefore, Valentini fabricated novel microelectrodes - coated homogeneous layers of single-walled carbon nanotubes ${ }^{25}$, while Chen and o-workers developed a simple method to get highly sensitive carbon fiber nanoelectrodes modified by single-walled carbon nanotubes. ${ }^{26}$ The modified electrode showed high sensitivity and favourable electrochemical behaviour toward DA. On the other hand, Wang reported selective determination of DA and serotonin, using carbon nanotube-intercalated graphite electrodes ${ }^{27}$. Self-assembled monolayer has been widely used in the fabrication of electrochemical sensors because it can provide a means of controlling the chemical nature of the electrode-solution interface and it prepares molecularly tailored interfaces with controlled spatial and geometric structure ${ }^{28-31}$. Ohsaka immobilized gold nanoparticles on a cystamine-terminated self-assembled monolayer on a polycrystalline Au electrode. The nano-Au electrode distinguishes the voltammetric signals of ascorbic acid and DA, which are indistinguishable at the bare Au electrode. ${ }^{32}$ Dong and co-workers determined DA at an in-site functionalized self-assembled monolayer on a gold electrode. ${ }^{33}$ The functionalized electrode exhibited electrocatalytic responses towards DA, reducing the overpotentials by $0.22 \mathrm{~V}$.

In this paper, we describe the use of L-cysteine modified electrode to form a novel thin-film material at a GC electrode for electroanalytical determination of DA. Herein, we studied two kinds of cysteine modified electrodes and their behaviour at different buffer solutions to obtain the best conditions about the preparation electrode and $\mathrm{pH}$ 
response. The modified electrode showed good catalytic activity to DA. This method has advantages of rapid and simple operation, and high accuracy. This modified film is considered to be a low-cost, steady, and promising material in the modification of electrodes.

\section{Experimental}

\subsection{Reagents}

Ultrapure water was obtained by Simplicity water purification system. Chemicals were of the highest quality commercially available, and were used without further purification. Nafion and ethanol were purchased from Sigma. L-cysteine, $\mathrm{H}_{2} \mathrm{SO}_{4}, \mathrm{H}_{2} \mathrm{NaPO}_{4}$ and $\mathrm{HNa}_{2} \mathrm{PO}_{4}$ were purchased from Fluka. Aqueous solutions were prepared using double-distilled deionised water and purged with nitrogen gas prior to each experiment. The buffer solutions were prepared from $\mathrm{H}_{2} \mathrm{NaPO}_{4}$, $\mathrm{HNa}_{2} \mathrm{PO}_{4}$, acetic acid, sodium acetate, sodium hydroxide, potassium hydrogen phthalate and hydrochloric acid reagents. Phosphate buffer solutions (PBS) with pH ranking about 2-6, acetate buffer solutions (ABS) from 3-6 and phthalate buffer solutions (PBS) were $\mathrm{pH}$ adjusted with $\mathrm{HCl}$ or $\mathrm{NaOH}$ to obtain a range from 4-8. The DA $0.01 \mathrm{M}$ solution was prepared using PBS ( $\mathrm{pH} 7$ ) solutions, as solvent. These solutions were preformed with double distilled water immediately prior to each experiment. Different buffer solutions at various $\mathrm{pH}$ values were used as a kind of supporting electrolyte for exploring the electrochemical behaviour of DA at modified electrodes.

\subsection{Apparatus and procedures}

Cyclic voltammetry (CV) was performed with an Autolab ${ }^{\circledR}$ PGSTAT40, connected to a PC. All electrochemical experiments employed a conventional three-electrode system consisted of an $\mathrm{Ag} / \mathrm{AgCl}(3.0 \mathrm{M})$ reference electrode, a platinum wire counter electrode and the working electrode (glassy carbon (GC); Nafion ${ }^{\circledR}$ modified glassy carbon (Nafion-GC) or L-cysteine-modified glassy carbon (Cys-MGC) electrode with a diameter of $2.0 \mathrm{~mm}$ ). The experiments were conducted at room temperature $\left(22 \pm 2{ }^{\circ} \mathrm{C}\right)$. The $\mathrm{pH}$ of the solution was measured by a $\mathrm{pH}$ meter. All potentials reported in this paper were referenced to the $\mathrm{Ag} / \mathrm{AgCl}$.

\subsection{Fabrication of the Cysteic Acid-modified glassy carbon (Cys-GC) electrode}

The surface of GC electrodes was first polished with alumina slurry and sonicated with deionised water for 5 minutes. After sonication, electrodes were rinsed with deionised water and allowed to dry in the air. Two kinds of L-cysteine modified electrodes were prepared by cycling the electrode potential between -1.2 and $2.6 \mathrm{~V}$ (five cycles) at the scan rate of $100 \mathrm{~m} \cdot \mathrm{V} / \mathrm{s}$ in $0.04 \mathrm{M} \mathrm{HCl}\left(\mathrm{Cys}-\mathrm{MGC}_{\mathrm{HCl}}\right)$ or PBS $(\mathrm{pH} 7)$ buffer $\left(\right.$ Cys-MGC ${ }_{\mathrm{PBS}}$ ) solutions containing $5.0 \times 10^{-3} \mathrm{~mol}_{\mathrm{L}} \mathrm{L}^{-1}$ of L-cysteine ${ }^{34,35}$. Figures $1 \mathrm{a}$ and $\mathrm{b}$ show the cyclic voltammograms of L-cysteine at bare GC electrodes. After 10 consecutive cycles, the surfaces of the GC electrodes were covered with a certain blue substance. The modified electrodes were then rinsed with ethanol and distilled water to remove the physically adsorbed and no reacted species from the electrode surface. Modified electrodes were electroactivated by cyclic scanning from $-0.50 \mathrm{~V}$ to $+0.80 \mathrm{~V}$ (two cycles) in a fresh supporting electrolyte solution (PBS or $\mathrm{HCl}$ ) at $50 \mathrm{~m} \cdot \mathrm{V} / \mathrm{s}$ and a steady cyclic voltammogram was obtained.

In the case of Nafion-GC electrode, the surface coating was prepared by applying $3.0 \mu \mathrm{L}$ of Nafion ${ }^{\circledR}$ solution $1.25 \%$. Nafion $\left(5 \% \mathrm{w} . \mathrm{V}^{-1}\right.$ solution, Aldrich) was diluted with ethanol. The coating was allowed to dry in air for 15 minutes. Before use, the Nafion-GC electrode was equilibrated for about 5 minutes in the supporting electrolyte solution. This electrode was prepared by comparison with other electrodes.

\section{Results and Discussions}

\subsection{Modification of GC electrode by Cysteic-Acid}

Many electrochemical researchers have been devoted to the determination of cysteine $(1)^{36,37}$. And it is widely accepted that the reaction occurs by the oxidation reaction mechanism on electrodes reported by several authors, according to follow Scheme 1..$^{37-40}$

The group SH of L-cysteine is oxidized (4) and two molecules are absorbed at the electrode surface (5) and forming a L-cystine (1). This mechanism can be verified by the electrochemical measurements (Figure 1) performed under experimental conditions specified in the experimental section. Figure 1 shows the cyclic voltammograms of covalent modification of glassy carbon surface electrode using L-cysteine solutions prepared in $\mathrm{PBS}$ and $\mathrm{HCl}$ as supporting electrolyte. This Figure indicates an irreversible oxidation peak at ca. $+0.7 \mathrm{~V}$ at the first segment, which implies that L-cysteine (1) was oxidized to L-cystine (6), and indicating that the species obtained after the first electron transfer undergoes a chemical reaction. The modification process was almost finished after three cycles. On the other hand, other irreversible oxidation peak was observed at ca. $+1.6 \mathrm{~V}$ with further voltammetric cycling. This behaviour was achieved at both GC electrodes using the two L-cysteine solutions; however, the oxidation of L-cysteine was faster using PBS as supporting electrolyte than the other one. The oxidation peak response decreased quickly with the successive scanning till the third times (Figure 1a, Cys- $\mathrm{MGC}_{\mathrm{PBS}}$ electrode). This is attributed to the passivation of the electrode related to the grafting of cysteine on the surface of GC electrode. Nevertheless, other factors due to be taken into consideration about the L-cysteine oxidation and adsorption on the electrode surface, which are discussed in the next section.

It is important to remark that other authors have proposed other mechanisms, where they have considered that one-electron oxidation of the amino group turns into its corresponding cation radical. These cation radicals form carbon-nitrogen links at the carbon electrode surface $^{41}$, as indicated below. Again, the oxidation peak response decreased with the successive scanning, indicating the passivation
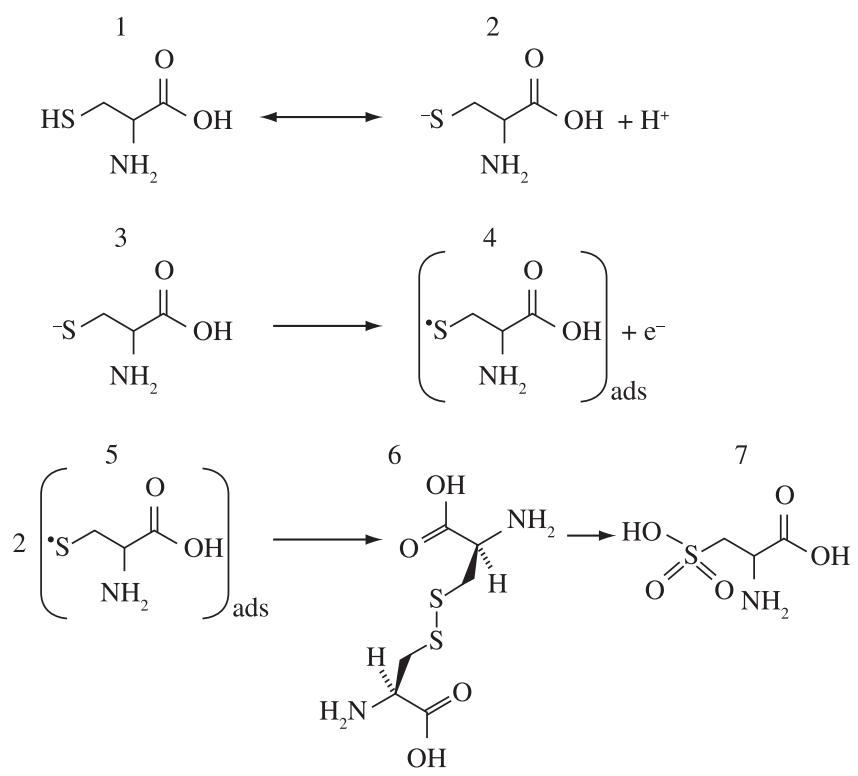

Scheme 1. L-cysteine oxidation mechanism at GC electrode surface. 
of the electrode. The modification of a GC electrode with aminecontaining compound suggests that diffusion rates as well as steric effects are most significant factors affecting the immobilization of amine-containing compounds at GC electrode surface; decreasing the mechanism accomplishment, according to follow Scheme 2.

In other cases, cysteic acid was found as an oxidation product of L-cystine (as can be observed from Scheme 1) ${ }^{38-40,43}$. Fei et al. determined that the oxidation product of cysteine can be further oxidized to chemisorbing molecules, cysteic acid (7), under a high positive potential ${ }^{40}$. Ralph et al. demonstrated that cysteine was adsorbed on the electrode by using AC voltammetry on GC electrode, and its further oxidation to cysteic $\operatorname{acid}^{39}$. On the other hand, using cyclic

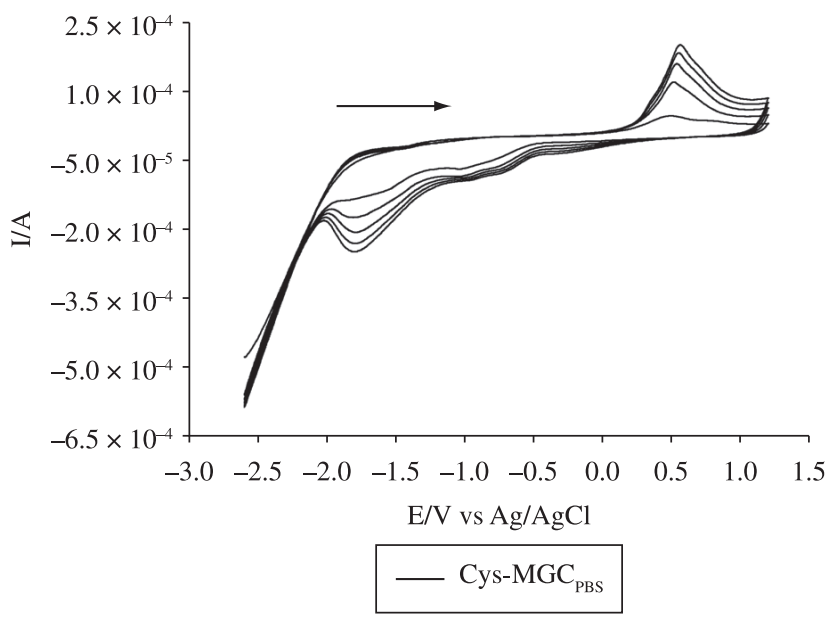

(a)

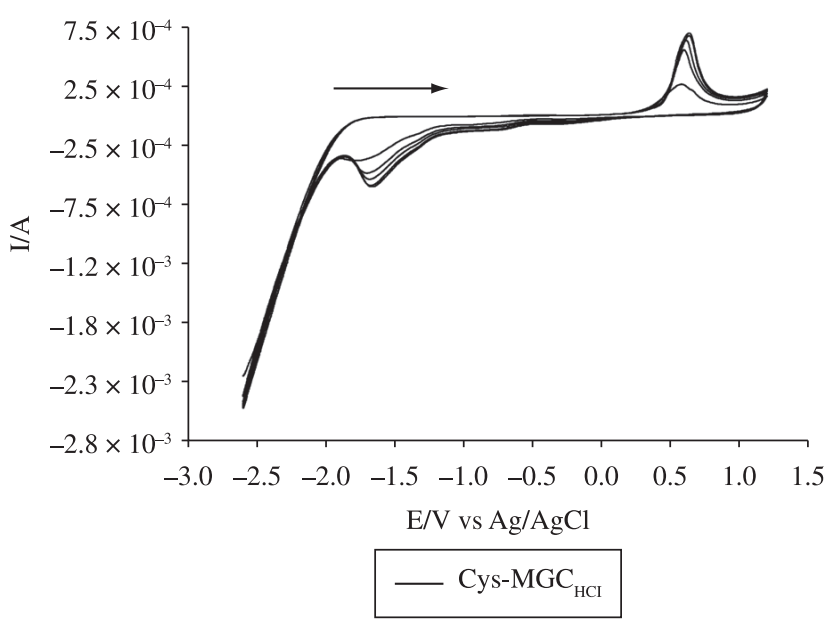

(b)

Figure 1. Cyclic voltammograms of the glassy carbon electrodes modified by cysteine in a) $0.04 \mathrm{M} \mathrm{HCl}$ and b) PBS containing $5.0 \times 10^{-3} \mathrm{~mol} . \mathrm{L}^{-1}$ of $\mathrm{L}$-cysteine; scan potential from -1.2 to $2.6 \mathrm{~V}$ and scan rate $100 \mathrm{~m} . \mathrm{V} / \mathrm{s}$. voltammetric and polarization measurements, Spataru et al. confirmed that the functional group, $\mathrm{SO}_{3} \mathrm{H}$, of cysteic acid (7) can be strongly adsorbed at GC electrode ${ }^{37}$. This mechanism is achieved using the L-cysteine solutions prepared with PBS, showing a fast decrease in the peaks response due to a high absorption rate. This outcome is in agreement with the data reported by us, where we observed this behaviour during the electrochemical preparation of modified electrode to $\mathrm{PBS}$ solution than $\mathrm{HCl}$ solution (see Figure 1).

Cysteic acid based on the electrochemical oxidation of cysteine is similar to Nafion with a sulfonated group, and it can be used as a novel electrode modifier due to its attractive ion-exchange characteristics. However, Nafion is more expensive than cysteine. Therefore cysteic acid film has more significant advantages and electroanalytical application than Nafion film.

\subsection{Adsorption of cysteine at electrode surface}

Although preparation of modified glassy carbon surface by L-cysteine oxidation have been studied for detecting and quantifying several compounds in the last years, the $\mathrm{pH}$ effects and supporting electrolyte on the covalent surface modification have not been addressed to a significant extent.

Several authors ${ }^{35,43-45}$, have achieved the covalent modification of GC surface using a specific supporting electrolyte solution $(\mathrm{HCl}$, PBS or $\mathrm{NBu}_{4} \mathrm{BF}_{4}$ ) containing a particular concentration of L-cysteine. The results separately reported by each author, have demonstrated the good performances in response of the cysteine modified GC electrodes for detecting some analytes. Therefore, we describe the use of L-cysteine modified electrode to form a novel thin-film material at a GC electrode for electroanalytical determination of DA (above section), studying two kinds of cysteine modified electrodes. We have compared the modification of the GC surface using two supporting electrolytes and based on the results obtained in Figure 1a and b, the process of covalent modification at GC surface electrode could be attained by two different mechanisms depending on the nature of the anion of the supporting electrolyte and the probable transformation of carbon surface (oxidation).

According to literature, it should be assumed that the nature of the anion of the supporting electrolyte that undergoes adsorption simultaneously with the oxygen and small oxygen molecules may essentially affect the ratio between components in a mixed adsorption layer. Experiments performed by Horanyi et al. ${ }^{46}$ in sulphuric acid solutions of different concentrations have proved that sulphate anions can force out products of adsorption of carboxylic acids. Under these conditions where the surface is blocked by anions of sulphuric acid, additional effects of the inhibition by atoms adsorbed oxygen may be manifested. Similar effect was observed to oxygen-amino molecules using like direct exposure to air, potentiodynamic and potentiostatic treatments in sulphuric acid, sodium hydroxide, phosphate and acetate buffers gave a response considerably smaller than that obtained at the freshly polished electrode ${ }^{47}$. Considering these figures, under our experimental conditions, a relatively adsorption layer process of anions of phosphate was attained ${ }^{48}$, transforming the GC surface from hydrophobic to hydrophilic with a chemically oxygenated<smiles>CC(NC(CS)C(C(=O)O)C(CS)[C@H](C)N)C(C(=O)O)C(CS)NC(CS)C(=O)O</smiles>

Scheme 2. Mechanism of oxidation of L-cysteine by one-electron from amino group. 
surface during the L-cysteine oxidation. Reaction proceeds through a specific surface interaction available on the hydrogen-terminated surface and such surface interactions are blocked on the oxygenterminated surface, a "site-blocking effect" produced by the surface carbon-oxygen functionalities.

When the $\mathrm{pH}$ lies between 1.71 and 8.33 the majority of the cysteine species shows zero net charge ${ }^{49}$, as such in our experimental conditions (PBS as supporting electrolyte). Then, the presence of zwitterions around the electrode makes their mutual interaction possible as well as the subsequent formation of the film, as adsorption is not affected by the electrode charge (oxygenated surface). Therefore, once a certain critical concentration is reached, the amount of cysteine molecules located around the electrode will be enough to form a compact monolayer. This compact film appears as a result of the interactions between cysteine molecules surrounding the electrode and, especially, to the charge-charge interactions established between the $-\mathrm{NH}^{+3}$ group of a zwitterion with the $-\mathrm{COO}^{-}$group of the adjacent one. However, a strong adsorption of $\mathrm{SO}_{3} \mathrm{H}$ group of cysteic acid, formed during cysteine oxidation, at GC electrode could be attained ${ }^{37}$, avoiding the single adsorption of the cysteine layer film and modifying its compact and uniform formation. Models with the $\mathrm{S}$ atoms oriented over a plane towards the electrode surface with this type of intermolecular bonding show this molecule arrangement as stereochemically possible, as reported by Stankovich and Bard ${ }^{50}$. Also, similar behaviour has been demonstrated using mercury electrodes ${ }^{49}$. Then, these assumptions can be confirmed from Figure 1a, the oxidation/adsorption processes of cysteine/cysteic acid occur quickly at GC surface than that obtained by HCl-Cysteine supporting electrolyte solution (Figure 1b). At later case, mildly modification of GC surface to oxygen-terminated surface is attained with $\mathrm{HCl}$ as supporting electrolyte; however, at $\mathrm{pH}$ below 1.71 , cysteine presents a positive charge. The positive charge of cysteine produces coulombic repulsion between these species and prevents their association. This positive charge is attracted by the negatively charged oxygen electrode surface, thus favouring the formation of a cysteine compact film around the electrode. This behaviour is confirmed from Figure 1b, which shows a gradual adsorption of cysteine on GC surface; but with an increase in the current values due to the specific interaction of oxygen terminal surface with the positive groups of cysteine at acidic conditions. This outcome is in agreement with the data reported by Zhang ${ }^{43}$.

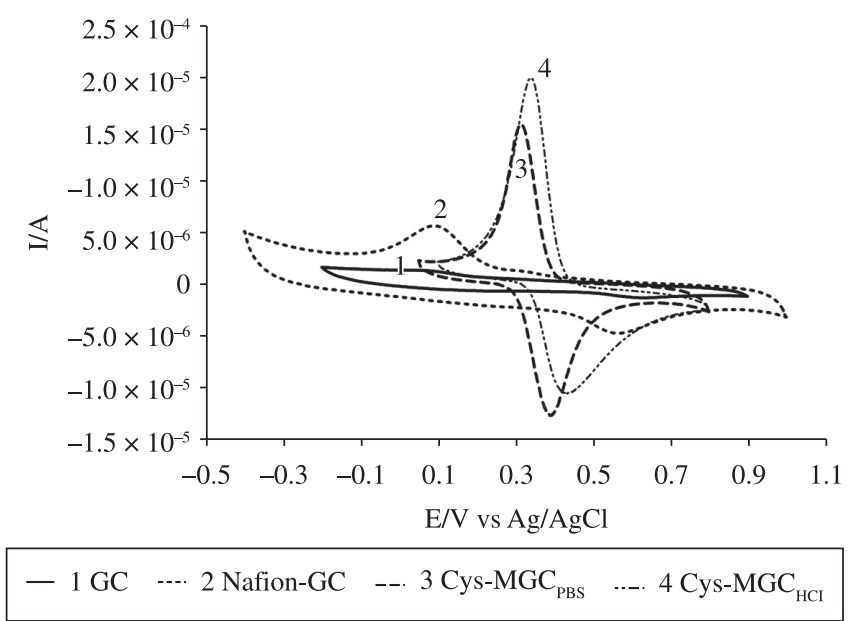

Figure 2. Cyclic voltammograms of $8.0 \times 10^{-5} \mathrm{~mol} . \mathrm{L}^{-1} \mathrm{DA}$ at Cys-MGC, Nafion-GC and bare GC electrodes. Scan potential from -0.4 to $1.0 \mathrm{~V}$ and scan rate: $50 \mathrm{~m} . \mathrm{V} / \mathrm{s}$. Supporting electrolyte: $\mathrm{PBS}(\mathrm{pH}=6)$.
We have provided a detailed study of the effect of $\mathrm{pH}$ on cyclic voltammograms at each L-cysteine modified electrode using different supporting electrolytes. But, the development of a new electrochemical method of analysis requires knowing the factors which are responsible for the electrochemical behaviour of the analyte (e.g. DA) and the way of control these factors in order to optimise the method. Therefore, we have studied the electrochemical behaviour of DA at both modified GC electrodes in order to select the better sensor.

\subsection{Cyclic voltammetric comparison behaviour of DA at GC, Cys-MGC and Nafion-GC electrodes}

Preliminary cyclic voltammetric experiments were performed to study the DA voltammetric behaviour at GC, Cys-MGC (Cys-MGC ${ }_{\mathrm{PBS}}$ and Cys- $\mathrm{MGC}_{\mathrm{HCl}}$ ) and Nafion-GC electrodes. It is important to remark that, in several investigations have been studied the DA behaviour and detection at $\mathrm{pH}$ range from 5-7, mimicking physiological $\mathrm{pH}$ because in these conditions the DA detection can be directly feasible in the biological fluids. For that reason, in this section was carried out in PBS $(\mathrm{pH}=6)$ medium to study the electrochemical behaviour at bare and modified electrodes. Moreover, DA is present in its protonated form at these conditions, favouring the accumulation in the modified electrodes. One of the first steps in our multitasked project is to characterize the electrochemical kinetics of DA at unmodified and modified GC electrodes in order to demonstrate the effectiveness of Cys-MGC respect to Nafion- GC electrodes.

Figure 2 allows comparing a series of cyclic voltammetric $i$ - $E$ curves for DA at these electrodes. The solution concentration was $200 \mu \mathrm{L}$ of $0.01 \mathrm{M}$ DA in $25 \mathrm{~mL}$ of PBS $=\mathrm{pH}$ 6. As it can be seen, the Cys-MGC electrodes offer higher peaks height than that observed at a Nafion modified GC electrode. The oxidation potential at the Nafion-GC electrode seems slightly shifted to both potential directions and it determines a minor reversibility of DA at this modified electrode, $\Delta E p=0.46 \mathrm{~V}$ (curve 2, Figure 2), where $\Delta E p$ is a difference between the anodic peak potential $\left(E_{\mathrm{pa}}\right)$ and the cathodic peak potential $\left(E_{\mathrm{pc}}\right)$. Whereas, at Cys-MGC electrodes, the DA reversibility was increased, showing a $\Delta E p$ of $\cong 0.070 \mathrm{~V}$ (curve 3 and 4, Figure 2). However, Cys- $\mathrm{MGC}_{\mathrm{HCl}}$ electrode showed modest improvements in the DA response respect to Cys- $\mathrm{MGC}_{\mathrm{PBS}}$. Also, both modified electrodes

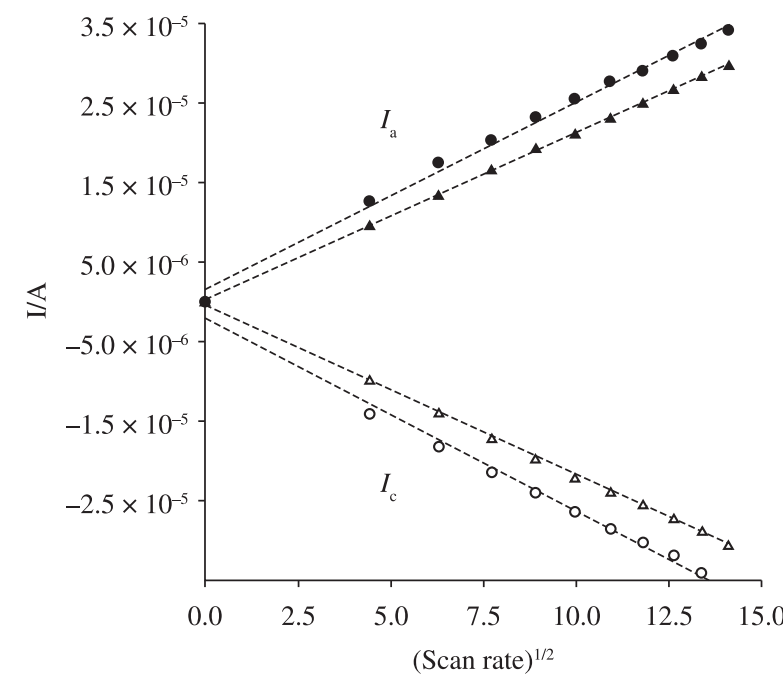

Figure 3. Plot of the anodic (Ia) and cathodic (Ic) peak currents versus scan rates in the range of 20 to $120 \mathrm{mV} . \mathrm{s}^{-1}$. Solution: $8.0 \times 10^{-5} \mathrm{~mol} . \mathrm{L}^{-1} \mathrm{DA}$ in PBS (pH 6) at $25^{\circ} \mathrm{C}$. Cys-MGC electrodes: $(\boldsymbol{\Lambda}, \Delta)$ Cys-MGC ${ }_{\mathrm{PBS}}$ and $(\circ, \bullet)$ Cys- $\mathrm{MGC}_{\mathrm{HCl}}$. 


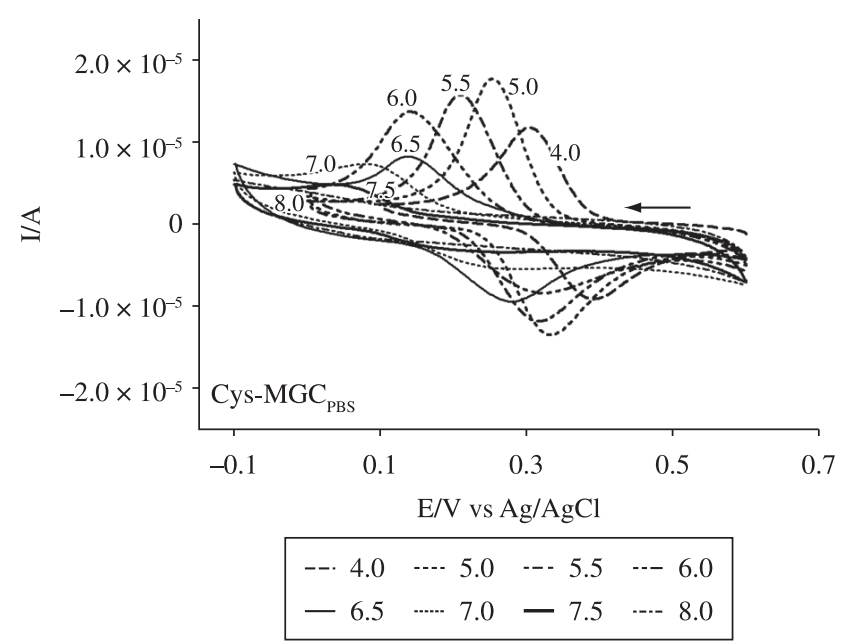

(a)

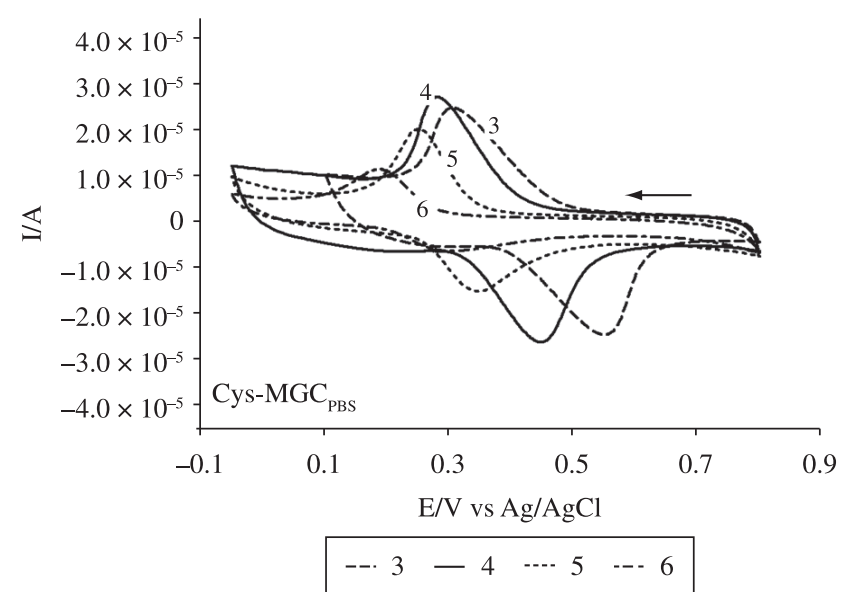

(c)

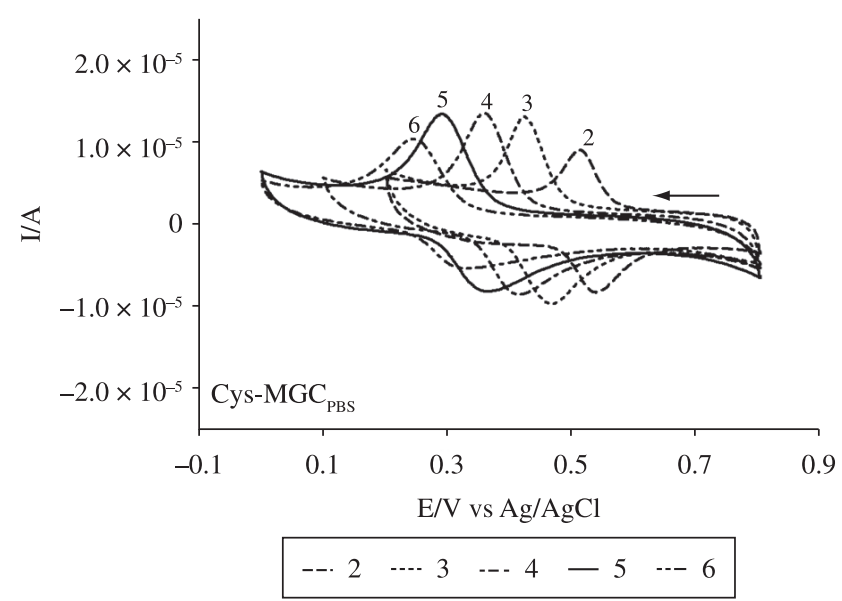

(e)

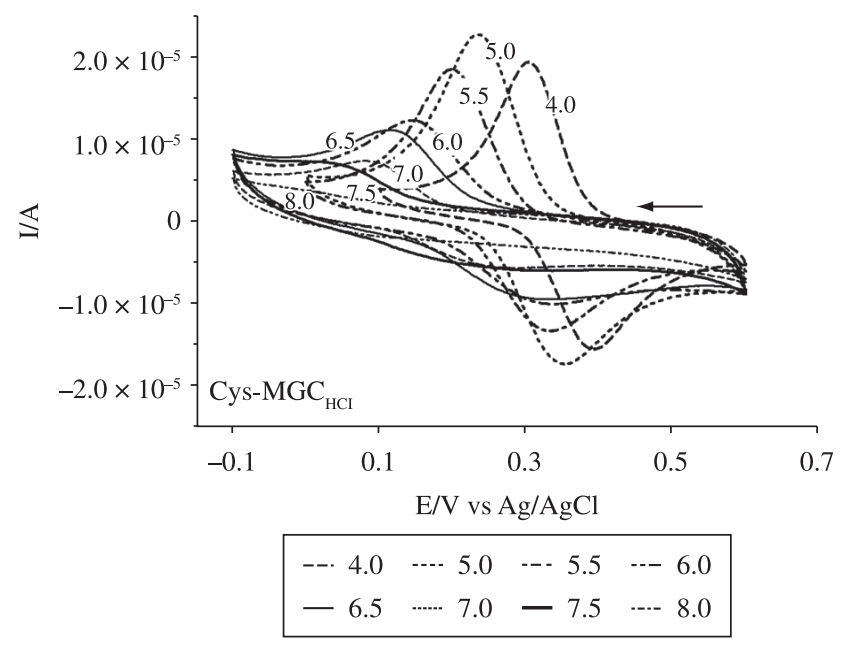

(b)

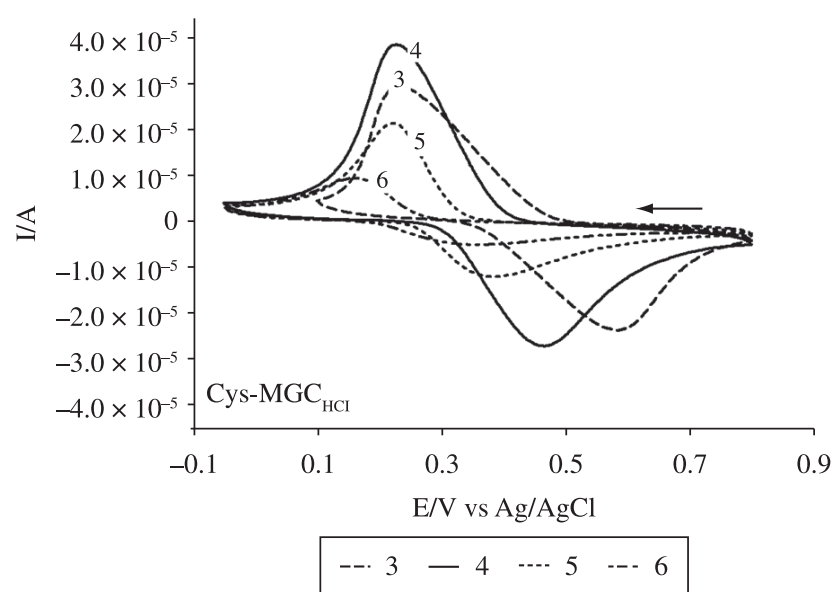

(d)

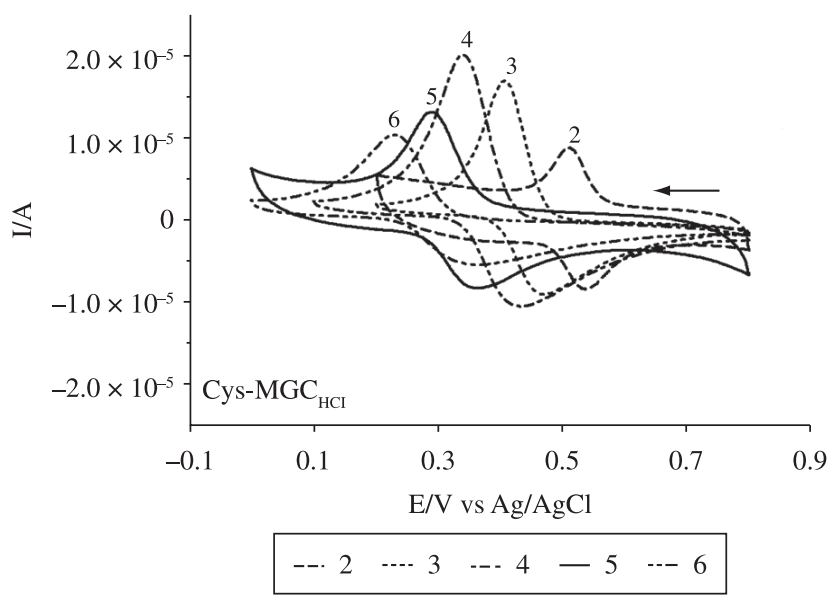

(f)

Figure 4. Effect on $\mathrm{CV}$ current peaks of $\mathrm{DA}$ at Cys-MGC electrodes $\left(\mathrm{Cys}-\mathrm{MGC}_{\mathrm{PBS}}\right.$ and $\left.\mathrm{Cys}-\mathrm{MGC}_{\mathrm{HC}}\right)$ as a function of pH. Cyclic voltammograms of DA were recorded in a series of buffer solutions: phthalate (a and b); acetate ( $c$ and d) and phosphate (e and f). The solution concentration was $200 \mu \mathrm{L}$ of $0.01 \mathrm{M}$ DA in $25 \mathrm{~mL}$, scan rate of $100 \mathrm{mV} / \mathrm{s}$ and at $25^{\circ} \mathrm{C}$. 
clearly showed higher improvements in response respect to GC electrode $(\Delta E p=0.58 \mathrm{~V}$; curve 1 , Figure 2). It is important to mention that, this response was observed immediately upon introducing DA solution into the electrochemical cell at Cys-MGC electrodes, and no time-dependent changes in the response were observed. The DA voltammetry has been measured at other electrodes only after long equilibration times, such as Nafion. For these reasons, is evident that Cys-MGC electrode has more significant advantages and electroanalytical application than Nafion film.

\subsection{Cyclic voltammetric behaviour of DA at the Cys-MGC electrodes}

Under the previously described experimental conditions, the cyclic voltammograms $(\mathrm{CV})$ recorded using $8.0 \times 10^{-5} \mathrm{~mol} \cdot \mathrm{L}^{-1} \mathrm{DA}$ in $25 \mathrm{~mL}$ of $\mathrm{PBS}=\mathrm{pH}$ 6, with a bare $\mathrm{GC}$ and both Cys-MGC electrodes $\left(\right.$ Cys- $\mathrm{MGC}_{\mathrm{PBS}}$ and $\mathrm{Cys}-\mathrm{MGC}_{\mathrm{HCl}}$ ) are shown in the Figure 2. As shown in this Figure, curve 1, a much broad and smaller $\mathrm{CV}$ peak response with a $500 \mathrm{mV}$ (scan rate of $100 \mathrm{mV} / \mathrm{s}$ ) was observed at bare GC electrode, indicating that there was not a reversible electrochemical behaviour of DA at this electrode. While the Cys-MGC electrodes leads to an obvious increase in $\mathrm{CV}$ peak response and a more reversible behaviour for DA in CV (curve 3 and 4, Figure 2), with a pair of well-defined redox waves of DA and with $\Delta E p \approx 70 \mathrm{mV}$, showing that the reversibility of DA was significantly improved respect to GC electrode (curves 1, Figure 2). This behaviour (changes of peak currents and the decreases in the $\Delta E p$ ) can be attributed to more favourable interactions between DA and the negatively charged monolayer formed in the Cys-MGC electrodes surface, indicating the strongly electrocatalytic function of these electrodes.

This performance can be also explained with distribution diagram for the DA species as a function of $\mathrm{pH}$, where at $\mathrm{pH}$ values higher than 7 , the concentration of the protonated form is present together the second specie and this probably difficult the incorporation in the negatively charged polymer ${ }^{51}$. It is also illustrated by Scheme 3 . Therefore, changed in the $\mathrm{pH}$ influences the peaks height, as expected on the basis of the pKa value; higher concentration of the protonated forms are present at lower $\mathrm{pH}$ that can be more easily incorporated in the cation exchanged polymer. As previously reported ${ }^{52}$, lowering the $\mathrm{pH}$ results in the formation of protonated carbonium ions.

Then, the surface-active group of cysteic acid can attract DA into the thin film, and the electron-transfer kinetic is enhanced. However, in most cases, the solution $\mathrm{pH}$ is important to the electrochemical
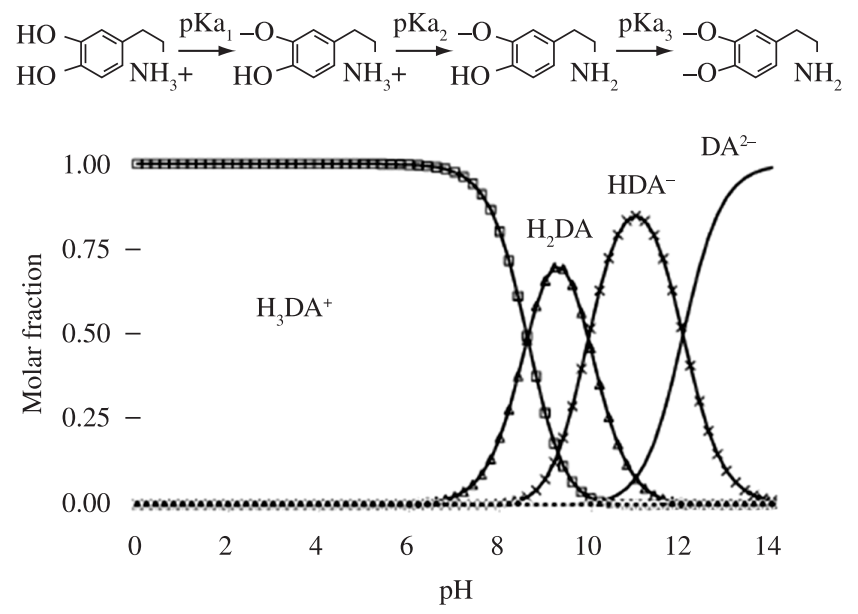

Scheme 3. Distribution of DA species as function of $\mathrm{pH}$. reaction and the response of DA towards modified electrodes. For that reason, the electrochemical behaviour of modified electrode for DA as function of $\mathrm{pH}$ and supporting electrolyte will be studied.

\subsection{Effect of the scan rate on the determination of DA}

The scan rate effect on the peak current of $8.0 \times 10^{-5} \mathrm{~mol} \cdot \mathrm{L}^{-1} \mathrm{DA}$ at the Cys-MGC electrodes (Cys-MGC ${ }_{\mathrm{PBS}}$ and $\left.\mathrm{Cys}-\mathrm{MGC}_{\mathrm{HCl}}\right)$ was also investigated, under similar experimental conditions described in first sections. Anodic and cathodic peak currents increased with increasing the scan rate at both Cys-MGC electrodes was achieved, as can be seen in Figure 3. A good linearity between $i_{\mathrm{p}}$ and the scan rate, $v$, was obtained from the range of $20-120 \mathrm{mV} / \mathrm{s}$, which demonstrates that the electrode reaction was an adsorption-controlled process.

Furthermore, after the Cys-MGC electrodes $\left(\mathrm{Cys}-\mathrm{MGC}_{\mathrm{PBS}}\right.$ and Cys- $\mathrm{MGC}_{\mathrm{HCl}}$ ) were used for $\mathrm{CV}$ scanning for one cycle in $\mathrm{pH} 6 \mathrm{PBS}$ containing $8.0 \times 10^{-5} \mathrm{~mol} . \mathrm{L}^{-1} \mathrm{DA}$, or immersed into the same solution for $30 \mathrm{~s}$, and then rinsed with distilled water, the response of DA could still be observed in PBS ( $\mathrm{pH}$ 6) without DA. This experimental result further indicated that the DA could be absorbed onto the modified electrode surface. The Cys-MGC electrodes could be refreshed after it was performed 80 cycles scanning in PBS ( $\mathrm{pH}$ 6). The influence of accumulation time on peak current of DA was examined in 0.1 mol.L $\mathrm{L}^{-1}$ PBS containing $8.0 \times 10^{-5}$ mol. $\mathrm{L}^{-1} \mathrm{DA}$. The peak current reached maximum after immersing Cys-MGC electrodes into solution for 1 minute. Hence, 60 seconds were chosen as the optical accumulation time. The $E_{\mathrm{pa}}$ shifted to more positive values with increasing the scan rate $(v)$, suggesting that the electron transfer was quasi-reversible. The transfer coefficient (i.e. $\alpha$ ) and the number of electrons involved in the rate-determining step can be evaluated. Based on the slope of $E_{\mathrm{pa}}$ with $\log (v),(1-\alpha) n \alpha$ could be calculated to be 0.95 . Relating this value with the Tafel plot $(b=2.3 \mathrm{RT} /(1-\alpha) n \alpha F)$, a slope of $65.4 \mathrm{mV}$ per decade was obtained. If $\alpha$ was assumed equal to $0.5, n \alpha$ was equaled to 1.89 . It indicated that the redox reaction of DA on the Cys-MGC electrodes is two protons coupled two electrons process.

\subsection{Effect of $\mathrm{pH}$ on the voltammetric response of DA}

The $\mathrm{pH}$ value of the base solution has a significant influence on the oxidation of DA at the Cys-MGC electrodes $\left(\mathrm{Cys}-\mathrm{MGC}_{\mathrm{PBS}}\right.$ and Cys- $\mathrm{MGC}_{\mathrm{HCl}}$ ), by altering both the peak currents and the peak potentials as well as modified layer, so the effect of $\mathrm{pH}$ was studied in detail. All changes in $\mathrm{CV}$ peak currents with $\mathrm{pH}$ were reversible in the range of 2-8, at both Cys-MGC electrodes, under follow experimental conditions: the solution concentration was $200 \mu \mathrm{L}$ of $0.01 \mathrm{M}$ DA in $25 \mathrm{~mL}$, scan rate of $100 \mathrm{mV} / \mathrm{s}$ and at $25^{\circ} \mathrm{C}$. In addition, a series of buffer solutions (acetate, phosphate, phthalate) were used in order to obtain a point of view more extended about the effect of supporting electrolyte and $\mathrm{pH}$.

Figure 4 shows the effect of solution $\mathrm{pH}$ on the peak currents and potentials $\left(\Delta E_{\mathrm{p}}\right)$ examined by recording cyclic voltammograms of DA in a series of buffer solutions varying $\mathrm{pH}$ in the range from 2 to 8 depending on buffer solution. As can be seen in Figure 4, at both Cys-MGC electrodes, the $\mathrm{pH}$ variation shifts the peak potentials to less positive potentials with increasing $\mathrm{pH}$ (in all supporting electrolytes), demonstrating the direct dependence between them. On the basis of results on Figure 4, a synthetic representation of their effect on current peak and $\mathrm{pH}$ is given in Figure 5, for both investigated modified electrodes, Cys-MGC $\mathrm{PBS}_{\mathrm{P}}$ and Cys- $\mathrm{MGC}_{\mathrm{HCl}}$. For DA, when $\mathrm{pH}$ varied between 2 and 6 , the peak current increased monotonically (Figure 5a, b and c). This behaviour is due to the dissociation of surface-attached acidic groups and the simultaneous increase in electrostatic attraction occurring between DA and the electrode. Note that up to $\mathrm{pH} 7$, dopamine exists in its protonated form (see Scheme 3) and therefore is readily pre-concentrated on negatively charged coat- 

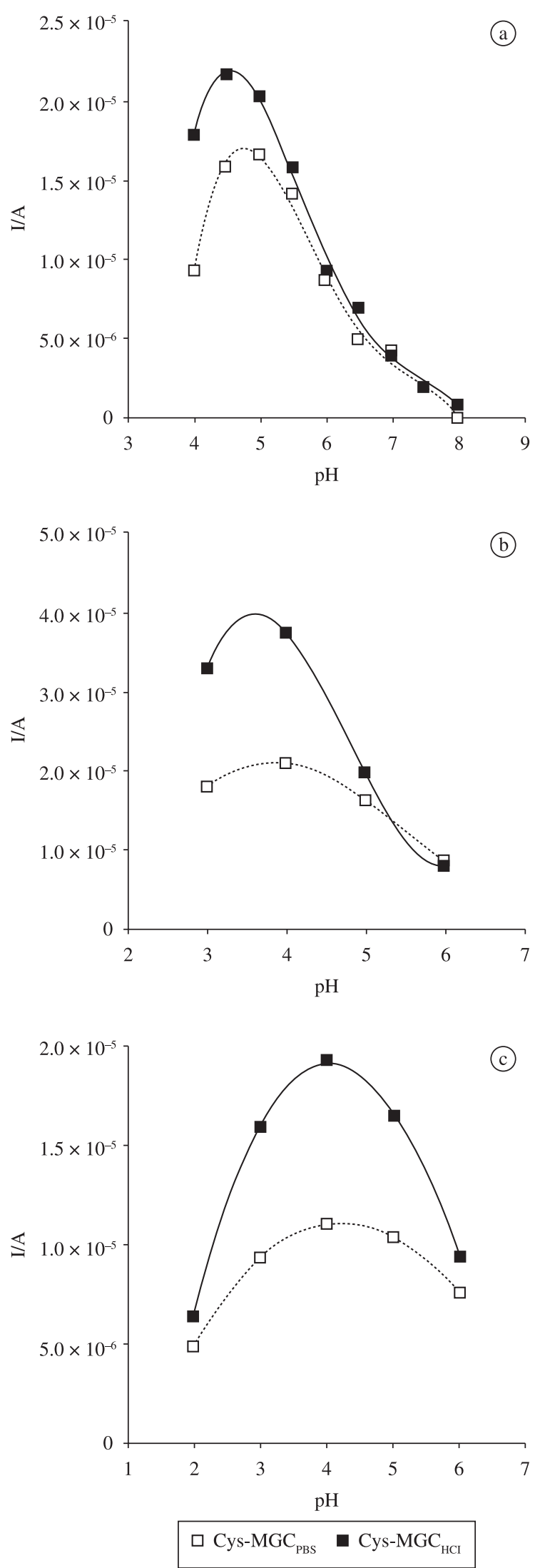

Figure 5. Synthetic representation of the current peaks as a function of $\mathrm{pH}$ at both modified electrodes. a) Buffer solutions; phthalate; b) acetate and c) phosphate .
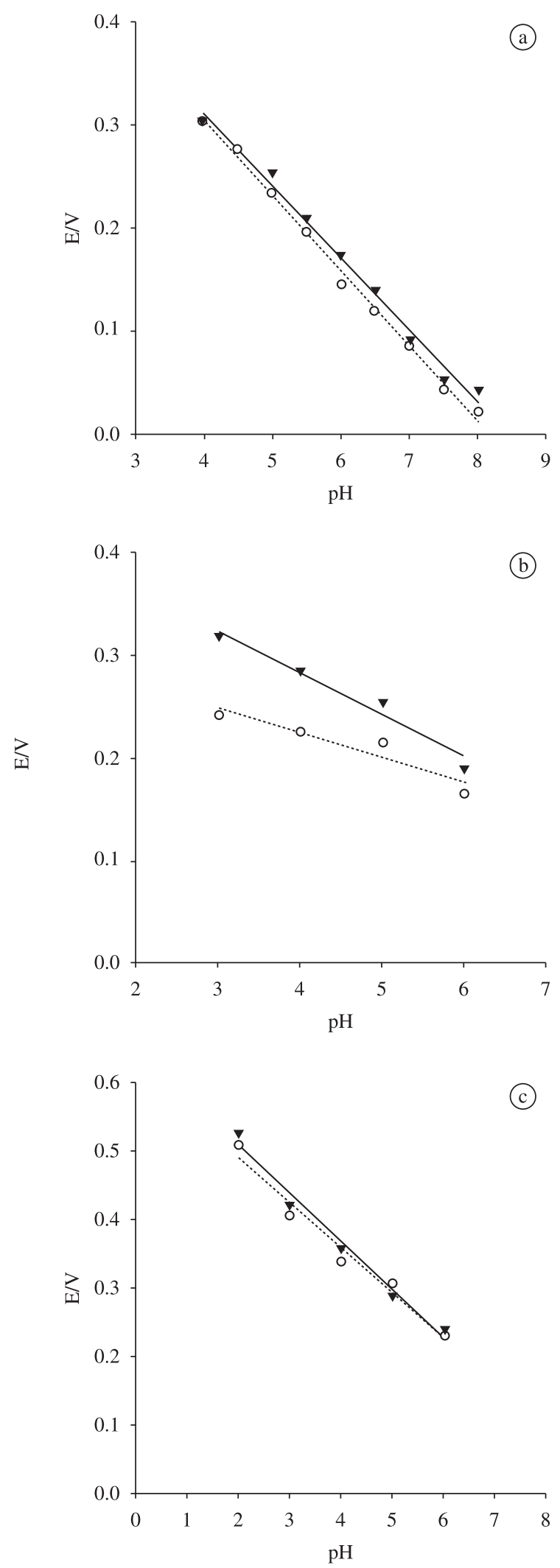

$\nabla$ Cys-MGC $_{\mathrm{PBS}} \circ \mathrm{Cys}-\mathrm{MGC}_{\mathrm{HCI}}$
Figure 6. Effect of peak potential (Epa) of DA response as a function of $\mathrm{pH}$ at both modified electrodes, Cys-MGC $\mathrm{PBS}$ and Cys-MGC $\mathrm{HCl}$ a) Buffer solutions phthalate; b) acetate and c) phosphate . 
ing formed at the glassy carbon surface. After that, when the $\mathrm{pH}$ was higher than 4-4.5, the peak response sharply decreased using acetate and phosphate buffer solutions as supporting electrolytes (Figure 5b and c). A similar $\mathrm{pH}$ response pattern was observed at phthalate buffer solutions. However, it increased monotonically between 4 and 5 and when $\mathrm{pH}$ passed 5.5, it also sharply decreased (Figure 5a). On the other hand, as it can be seen in Figure 5, the oxidation peak current at both modified electrodes, Cys- $\mathrm{MGC}_{\mathrm{PBS}}$ and $\mathrm{Cys}-\mathrm{MGC}_{\mathrm{HCl}}$, was very different where the current response at $\mathrm{Cys}-\mathrm{MGC}_{\mathrm{HCl}}$ showed significant improvements in voltammetric detection of DA. These results confirm the assumption explained in the section $b$, regarding the modification surface at Cys- $\mathrm{MGC}_{\mathrm{HCl}}$ electrode. The cysteine positive charge is attracted by the negatively charged oxygen electrode surface, thus favouring the formation of a cysteine compact film around the electrode. This behaviour was confirmed from Figure 1b, which shows a gradual adsorption of cysteine on GC surface; but with an increase in the current values due to the specific interaction of oxygen terminal surface with the positive groups of cysteine at acidic conditions. For this reason, the surface-active group at modified surface can attract DA into the thin film, and the electron-transfer kinetic is enhanced. In the case of acetate supporting electrolyte, recent studies have shown that the 3,4-dihydroxyphenylacetic acid was easily oxidized and DA anodic current decreased in acetate buffer than in phosphate buffer ${ }^{53}$, indicating the adsorption of phosphate on electrode surface, as discussed above. Therefore, the dependence of DA, electrochemistry on the supporting electrolyte is attributed to the competitive adsorption between the supporting electrolyte and DA, and the interaction between the adsorbed supporting electrolyte and DA. When acetate buffer was used as the supporting electrolyte, the interaction between the acetate and the cysteine-modified GC surface is not as strong as the interaction between phosphate and the Cys-MGC surface, shifting the DA current response to a similar value under different $\mathrm{pH}$ conditions.

Figure 6 shows that the peak potential for DA oxidation changes linearly with $\mathrm{pH}$ between 2 and 8 , and is shifted to more negative potentials with a slope of $-0.057 \mathrm{~V}$ per $\mathrm{pH}$ unit, which is very close to the theoretical value of $-0.059 \mathrm{~V}$ per $\mathrm{pH}$ unit for the two-electron, two proton process. As DA oxidation is known to occur by a twoelectron transfer, the number of protons involved was also predicted to be two ${ }^{31}$. This behaviour is attributed to the fact that DA exists in the cationic form $\left(\mathrm{p} K_{\mathrm{a}}\right.$ 8.9). The cysteine-modified GC electrode undertook negative charges, so the thin film could allow only cationic DA to reach the interface and repulse anionic. This is a very important factor for the real sample analysis, which must be performed at physiological $\mathrm{pH}$ or very similar $\mathrm{pH}$.

\subsection{Permeability}

Subsequently, the voltammograms in Figure 4 were used to determine the permeability of the modified electrodes, Cys-MGC $\mathrm{MBS}_{\mathrm{PBS}}$ and Cys- $\mathrm{MGC}_{\mathrm{HCl}}$, at different buffer solutions. The permeability, $P$, of a film to the redox probes was calculated from the expression reported by Gorski ${ }^{54}, P=\left[I_{\text {film }} / I_{\text {bare }}\right] \times 100$ where $I_{\text {film }}$ and $I_{\text {bare }}$ are the voltammetric peak currents recorded at the modified electrode and the bare GC, respectively. The two modified electrodes display an increased permselectivity to DA depending on $\mathrm{pH}$, as shows Figure 7. In the calculations, the $I_{\mathrm{pa}}$ currents were used for the voltamogramms at $100 \mathrm{mV} / \mathrm{s}$ (see Figure 3).

\subsection{Stability of modified electrodes}

The stability of Cys-MGC electrodes $\left(\mathrm{Cys}-\mathrm{MGC}_{\mathrm{PBS}}\right.$ and Cys$\mathrm{MGC}_{\mathrm{HCl}}$ ) also was examined in experiment. The modified electrodes were stored in the 0.1 mol.L $\mathrm{L}^{-1} \mathrm{PBS}(\mathrm{pH} 7)$ after every experiment. The cyclic voltammetric experiments were carried out using modified

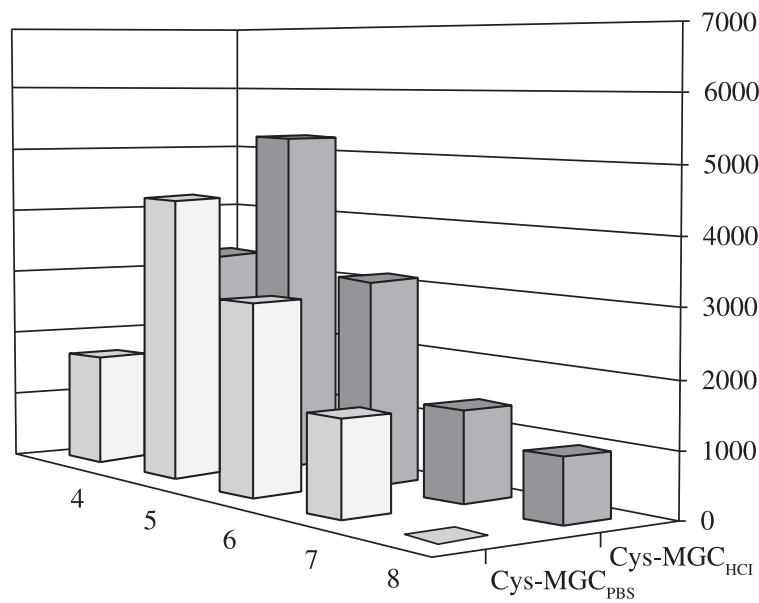

(a)

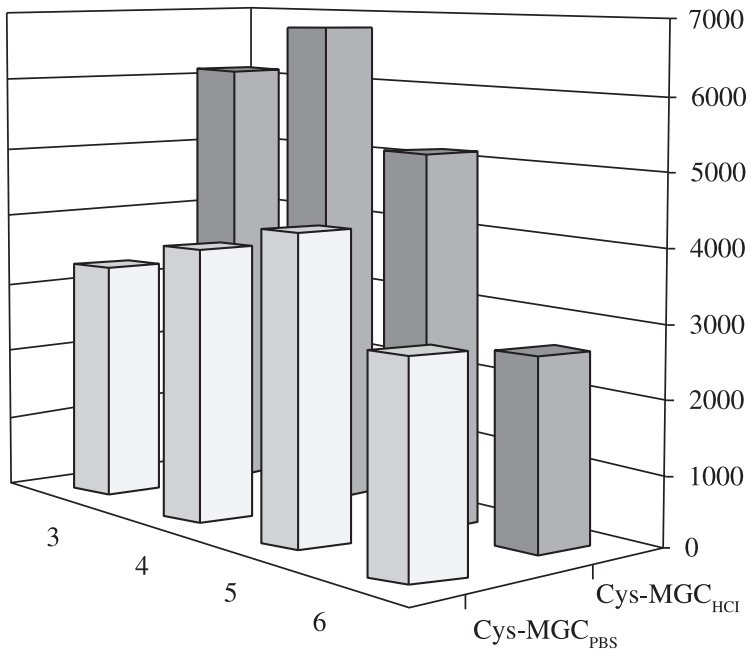

(b)

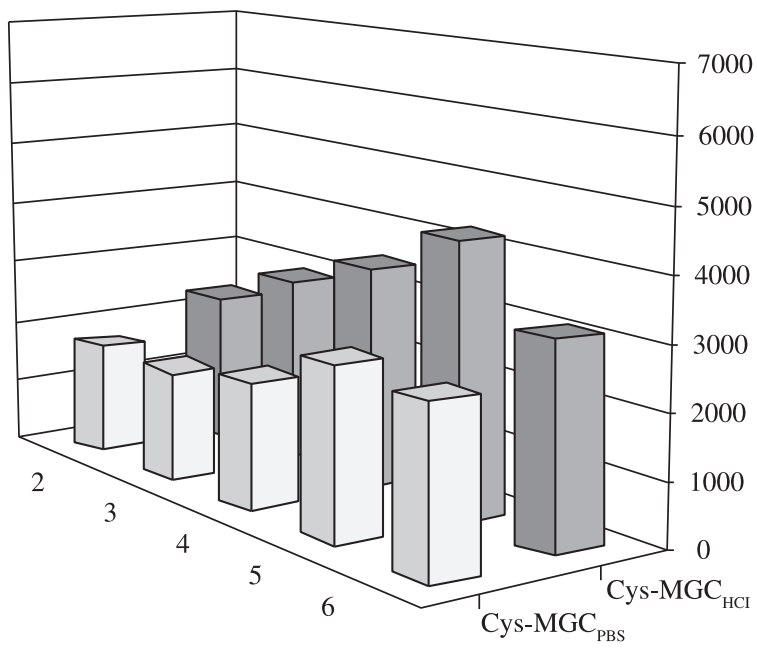

(c)

Figure 7. \% Permeability as a function of $\mathrm{pH}$ at both modified electrodes, Cys-MGC $\mathrm{PBS}_{\mathrm{PB}}$ and Cys-MGC $\mathrm{HCl}$. Buffer solutions: a) phthalate ; b) acetate and c) phosphate. where Ifilm and Ibare are the voltammetric peak currents recorded at the modified electrode and the bare GC, respectively. 
electrodes once a day at the same operation conditions. The anodic peak current of DA can hardly change for 5 weeks. It shows that the Cys-MGC electrodes $\left(\mathrm{Cys}-\mathrm{MGC}_{\mathrm{PBS}}\right.$ and $\mathrm{Cys}-\mathrm{MGC}_{\mathrm{HCl}}$ ) have a nicer stability, with relative standard deviation $(\mathrm{RSD})$ of $3.5 \%(\mathrm{n}=10)$,

\subsection{Calibration curve and detection limit}

Under optimal conditions, using the differential pulse mode and Cys- $\mathrm{MGC}_{\mathrm{HCl}}$ as electrode (due to its better performances achieved), the catalytic peak current was linearly dependent on the DA concentration over the range of $3.5 \times 10^{-9}$ to $5.0 \times 10^{-6} \mathrm{~mol} . \mathrm{L}^{-1}$. The linear equation is $\mathrm{i}_{\mathrm{pa}}(\mu \mathrm{A})=2.2+14.7 \mathrm{C}\left(10^{-6} \mathrm{~mol} . \mathrm{L}^{-1}\right)$ with a correlation coefficient, $r=0.998$. The detection limit of DA was $1.5 \times 10^{-9}$ mol. $\mathrm{L}^{-1}$. When the DA concentration was more than $5.5 \times 10^{-6}$ mol. $\mathrm{L}^{-1}$, the current response decreased gradually and its plateau was observed; this is attributed to the saturation of DA on the modified electrode.

\section{Concluding Remarks}

In summary, we present a novel sensor material that is based on cysteine oxidation for the covalent modification of GC electrode and it seems to offer a fast, reliable, economic and simple way for quantifying DA. The modification of GC surface depends on the $\mathrm{pH}$ and anions on the supporting electrolyte solution containing L-cysteine. From the results, $\mathrm{Cys}-\mathrm{MGC}_{\mathrm{HCl}}$ modified electrode seems to show better formation of compact film than Cys- $\mathrm{MGC}_{\mathrm{PBS}}$, due to the cysteine species formed and attached on surface at specific $\mathrm{pH}$ from $\mathrm{HCl}$ and PBS solutions. Also, the terminal oxygen surface produced during the application of electrical potential, during the cysteine oxidation, favours the orientation of the adsorption of cysteine species on surface. The film formed and the concentration capability of the layer, due to its affinity towards the analyte, produces a significant gain of sensitivity (respect to other polymer surface modification such as Nafion) and it can convert in an innovative and high-quality sensor and a powerful tool in biological, biotechnological, and medical research. After that, from the results obtained during DA detection, we can draw the following remarks: i) DA reversibility is increased at Cys-MGC electrodes that have more significant advantages and electroanalytical application than Nafion film; ii) DA response at Cys-MGC electrodes are strongly dependence on $\mathrm{pH}$ solution, but principally influenced by the film on GC surface; iii) Cys- $\mathrm{MGC}_{\mathrm{HC}}$ showed good performances in DA current response at all buffer solutions respect to Cys- $\mathrm{MGC}_{\mathrm{PBS}}$; however, Cys- $\mathrm{MGC}_{\mathrm{HCl}}$ showed significant current responses at acetate buffer solutions; iv) a calibration range from $3.5 \times 10^{-9}$ to $5.0 \times 10^{-6} \mathrm{~mol} . \mathrm{L}^{-1}$ and detection limit of $1.5 \times 10^{-9}$ mol. $\mathrm{L}^{-1}$ were established for DA detection.

Further studies are required to fully understand the factors that are involved in the electron transfer process of DA at Cys-MGC electrodes. These studies include the effect of ionic strength, interferences, and sensitive detection. Moreover, experiments will be performed to estimate other figures of merit (e.g. precision, uncertainty of measurement, selectivity, robustness, etc.). However, the results reported in this manuscript demonstrate the potential of modified electrodes for future application in chemical and biological sensors (e. g.: the in vitro/vivo application of this sensor) even though the detailed detection of DA needs further investigation.

\section{References}

1. Cooper JR, Bloom FE and Roth RH. The Biochemical Basis of Neuropharmacology.Oxford: Oxford University Press; 1982.

2. Damier P, Hirsch EC, Agid Y and Graybiel AM. The substantia nigra of the human brain: II. Patterns of loss of dopamine-containing neurons in Parkinson's disease. Brain. 1999; 122(8):1437-1448.
3. Wightman RM, May LJ and Michael AC. Detection of dopamine dynamics in the brain. Analytical Chemistry. 1998; 60(13):769A-755A.

4. Bone RG and Villar HO. Discriminating D1 and D2 agonists with a hydrophobic similarity index. Journal of Molecular Graphics. 1995; 13(3):201-208

5. Creese I, Burt DR and Snyder SH. The dopamine receptor: differential binding of d LSD and related agents to agonist and antagonist states. Life Sciences. 1975; 17(11):1715-1720.

6. Trumpp-Kallmeyer S, Hoflack J, Bruinvels A and Hibert M. Modeling of G-protein-coupled receptors: application to dopamine, adrenaline, serotonin, acetylcholine, and mammalian opsin receptors. Journal of Medicinal Chemistry. 1992; 35(19):3448-3462.

7. Abe T, Lau YY and Ewing AG. Characterization of glucose microsensors for intracellular measurements. Analytical Chemistry. 1992; 64(18):2160-2163.

8. Dale N, Hatz S, Tian F and Llaudet E. Listening to the brain: Microelectrode biosensors for neurochemicals. Trends in Biotechnology. 2005; 23(8):420-428.

9. Nohta H, Yukizawa T, Ohkura Y, Yoshimura M, Ishida J and Yamaguchi M. Aromatic glycinonitriles and methylamines as precolumn fluorescene derivatization reagents for catecholamines. Analytica Chimica Acta. 1997; 344(3):233-240.

10. Li J and Lu J. Flow-injection/chemiluminescene assays of catecholamines. Chinese Journal of Analytical Chemistry. 1997; 25(3):316-317.

11. Wu Y, Fan R and Di J. Electrochemical study of electron transfer between dopamine and ferrocene at liquid/liquid interface. Chinese Journal of Analytical Chemistry. 1996; 24(8):873-875.

12. Zhu R and Kok WT. Determination of catecholamines and related compounds by capillary electrophoresis with postcolumn terbium complexation and sensitized luminescence detection. Analytical Chemistry 1997; 69(19):4010-4016.

13. Angnes L, Azevedo CMN, Araki K and Toma HE. Electrochemical detection of NADH and dopamine in flow analysis based on tetraruthenated porphyrin modified electrodes. Analytica Chimica Acta. 1996; 329(1-2):91-95.

14. Yu AM, Sun DM and Chen HY. Electrochemical determination of dopamine in the presence of high concentrations of ascorbic acid at a poly (indole-3-acetic acid) coated electrode. Analytical Letters. 1997; 30(9):1643-1652.

15. Zen JM and Chen IL. Voltammetric determination of dopamine in the presence of ascorbic acid at a chemically modified electrode. Electroanalysis. 1997; 9(7):537-540.

16. Cai CX and Xue KH. Electrochemical characterization of pyrocatechol sulfonephthalein-modified glassy carbon electrode and separation of electrocatalytic responses for ascorbic acid and dopamine oxidation. Microchemical Journal. 1999; 61(3):183-197.

17. Cosnier S, Innocent C, Allien L, Poitry S and Tsacopoulos M. An electrochemical method for making enzyme microsensors: application to the detection of dopamine and glutamate. Analytical Chemistry. 1997; 69(5):968-971.

18. Luo H, Shi Z, Li N, Gu Z and Zhuang Q. Investigation of the electrochemical and electrocatalytic behavior of single-wall carbon nanotube film on a glassy carbon electrode. Analytical Chemistry. 2001; 73(5):915-920

19. Xun Z, Cai C, Xing W and Lu T. Electrocatalytic oxidation of dopamine at a cobalt hexacyanoferrate modified glassy carbon electrode prepared by a new method. Journal Electroanalytical Chemistry. 2003; 545(suppl.):19-27.

20. Granger MC, Witek M, Xu JS, Wang J, Hupert M, Hanks A et al. Standard electrochemical behavior of high-quality, boron-doped polycrystalline diamond thin-film electrodes. Analytical Chemistry. 2000; 72(16):3793-3804.

21. Roy PR, Saha MS, Okajima T, Park SG, Fujishima A and Ohsaka T. Selective detection of dopamine and its metabolite, DOPAC, in the 
presence of ascorbic acid using diamond electrode modified by the polymer film. Electroanalysis. 2004; 16(21): 1777-1784.

22. Weng J, Xue J, Wang J, Ye JS, Cui H, Sheu FS et al. Gold-cluster sensors formed electrochemically at boron-doped-diamond electrodes: detection of dopamine in the presence of ascorbic acid and thiols. Advanced Functional Materials. 2005; 15(8):1358-1363.

23. Sun D, Zhu Q, Zhang Z and Zhang Z. Preparation of poly(L-tryptophan)modified electrode and cyclic voltammetric determination of dopamine. Chinese Journal of Analytical Chemistry. 2003; 22(6):6-8.

24. Hocevar SB, Wang J, Deo RP, Musameh M and Ogorevc B. Carbon nanotube-modified microelectrode for enhanced voltammetric detection of dopamine in the presence of ascorbate. Electroanalysis. 2005; 17(5-6):417-422.

25. Valentini F, Orlanducci S, Tamburri E, Terranova ML, Curulli A and Palleschi G. Single-walled carbon nanotubes on tungsten wires: a new class of microelectrochemical sensors. Electroanalysis. 2005; 17(1):28-37.

26. Chen RS, Huang WH, Tong H, Wang ZL and Cheng JK. Carbon fiber nanoelectrodes modified by single-walled carbon nanotubes. Analytical Chemistry. 2003; 75(22):6341-6345.

27. Wang Z, Liang Q, Wang Y and Luo G. Carbon nanotube-intercalated graphite electrodes for simultaneous determination of dopamine and serotonin in the presence of ascorbic acid. Journal of Electroanalytical Chemistry. 2003; 540:129-134.

28. Wang Q, Dong D and Li N. Electrochemical response of dopamine at a penicillamine self-assembled gold electrode. Bioelectrochemistry. 2001; 54(2):169-175.

29. Wang Q, Jiang N and Li N. Electrocatalytic response of dopamine at a thiolactic acid self-assembled gold electrode. Microchemical Journal. 2001; 68(1):77-85.

30. Zhan $\mathrm{H}, \mathrm{Li} \mathrm{N}$ and Zhu Z. Electrocatalytic response of dopamine at a DL-homocysteine self-assembled gold electrode. Microchemical Journal. 2000; 64(3):277-282.

31. Liu T, Li M and Li Q. Electroanalysis of dopamine at a gold electrode modified with N-acetylcysteine self-assembled monolayer. Talanta. 2004; 63(4):1053-1059.

32. Raj CR, Okajima T and Ohsaka T. Gold nanoparticle arrays for the voltammetric sensing of dopamine. Journal of Electroanalytical Chemistry. 2003; 543(2):127-133.

33. Zhang L, Jia J, Zou X and Dong S. Simultaneous determination of dopamine and ascorbic acid at an in-site functionalized self-assembled monolayer on gold electrode. Electroanalysis. 2004; 16(17):1413-1418.

34. Wang CY, Wang ZX, Guan J and Hu XY. Voltammetric determination of meloxicam in pharmaceutical formulation and human serum at glassy carbon electrode modified by cysteic acid formed by electrochemical oxidation of L-cysteine. Sensors. 2006; 6(9):1139-1152.

35. Wang C, Li C, Wang F and Wang C. Covalent modification of glassy carbon electrode with L-cysteine for the determination of acetaminophen. Microchimica Acta. 2006; 155 (3-4):365-371.

36. Li H, Li T and Wang E. Electrocatalytic oxidation and flow detection of cysteine at an aquocobalarnin adsorbed glassy carbon electrode. Talanta. 1995; 42(7):885-890.

37. Spataru N, Sarada BV, Popa E, Tryk DA and Fujishima A. Voltammetric determination of L-cysteine at conductive diamond electrodes. Analytical Chemistry. 2001; 73(3):514-519.
38. Zagal J, Fierro C and Rozas R. Electrocatalytic effects of adsorbed cobalt phthalocyanine tetrasulfonate in the anodic oxidation of cysteine. Journal of Electroanalytical Chemistry. 1981; 119(2):403-408.

39. Ralph TR, Hitchman ML, Millington JP and Walsh FC. The electrochemistry of L-cystine and L-cysteine part 1: thermodynamic and kinetic studies. Journal of Electroanalytical Chemistry. 1994; 375(1-2):1-15.

40. Fei SD, Cheng JH, Yao SZ, Deng GH, He DL and Kuang YF. Electrochemical behavior of L-cysteine and its detection at carbonnanotube electrode modified with platinum. Analytical Biochemistry. 2005; 339(1):29-35.

41. Barbier B, Pinson J, Desarmot G and Sanchez M. Electrochemical bonding of amines to carbon-fiber surfaces toward improved carbonepoxy composites. Journal of the Electrochemical Society. 1990; 137(6):1757-1764.

42. Davis DG and Bianco E. An electrochemical study of the oxidation of L-cysteine. Journal of Electroanalytical Chemistry. 1996; 12(3):254-260.

43. Zhang L. Covalent modification of glassy carbon electrode with cysteine for the determination of dopamine in the presence of ascorbic acid. Microchimica Acta. 2008; 161(1-2):191-200.

44. Guan J, Wang Z, Wang C, Qu Q, Yang G and Hu X. Voltammetric determination of sinomenine at glassy carbon electrode modified by cysteic acid based on electrochemical oxidation of L-cysteine. International Journal of Electrochemcal Science. 2007; 2(8):572-582.

45. Wang C, Liu Q, Shao X and Hu X. Voltammetric determination of dopamine in human serum and urine at a glassy carbon electrode modified by cysteic acid based on electrochemical oxidation of L-cysteine. Analytical Letters. 2007; 40(4-6):689-704.

46. Horanyi G, Vertes G and Hegedüs D. Acta Chimica (Academiae Scientiarum) Hungaricae. 1973; 79:301.

47. Pedano ML and Rivas G. Immobilization of DNA on glassy carbon electrodes for the development of affinity biosensors. Sensors. 2005; 5(6-10):424-447.

48. Dai H and Shiu KK. Voltammetric studies of electrochemical pretreatment of rotating-disk glassy carbon electrodes in phosphate buffer. Journal of Electroanalytical Chemistry. 1996; 419(1):7-14.

49. Monterroso-Marco B and Lopez-Ruiz B. pH effect on cysteine and cystine behaviour at hangingmercury drop electrode. Talanta. 2003; 61(5):733-741.

50. Stankovich MT and Bard AJ. The electrochemistry of proteins and related substances I. Cystine and cysteine at the mercury electrode. Journal of Electroanalytical Chemistry. 1977; 75(2):487-505.

51. Sánchez-Rivera AE, Corona-Avendaño S, Alarcón-Angeles G, Rojas-Hernández A, Ramírez-Silva MT and Romero-Romo MA. Spectrophotometric study on the stability of dopamine and the determination of its acidity constants. Spectrochimica Acta. 2003; 59(13):3193-3203.

52. Ugo P and Moretto LM. Ion-exchange voltammetry at polymer-coated electrodes: Principles and analytical prospects. Electroanalysis. 1995; 7(12):1105-1113.

53. Xu G, Iwasaki Y and Niwa O. Selective electrochemical response of dopamine against 3,4-Dihydroxyphenylacetic acid at bare indium-tin oxide electrode. Chemistry Letters. 2005; 34(8):1120-1121.

54. Cruz J, Kawasaki M and Gorski W. Electrode coatings based on chitosan scaffolds. Analytical Chemistry. 2000; 72(4):680-686. 